\title{
Is dynamometry able to infer the risk of muscle mass loss in patients with COPD?
}

\author{
This article was published in the following Dove Press journal: \\ International Journal of COPD \\ 21 July 2015 \\ Number of times this article has been viewed
}

\author{
Dionei Ramos ${ }^{1}$ \\ Giovana Navarro Bertolini' \\ Marceli Rocha Leite' \\ Luiz Carlos Soares \\ Carvalho Junior \\ Paula Roberta da Silva \\ Pestana' \\ Vanessa Ribeiro dos Santos ${ }^{2}$ \\ Ana Claudia de Souza \\ Fortaleza ${ }^{2}$ \\ Fernanda Maria Machado \\ Rodrigues' \\ Ercy Mara Cipulo Ramos' \\ 'Department of Physiotherapy, São \\ Paulo State University, Presidente \\ Prudente, Brazil; ' ${ }^{2}$ Department \\ of Motricity Sciences, São Paulo State \\ University, Rio Claro, Brazil
}

Correspondence: Marceli Rocha Leite Departamento de Fisioterapia, Universidade Estadual Paulista, Rua Roberto Simonsen, Number 305, Presidente Prudente, São Paulo, 19060-900, Brazil

Email marcelirocha@hotmail.com
Introduction: Sarcopenia is characterized by a progressive and generalized decrease of strength and muscle mass. Muscle mass loss is prevalent in patients with chronic obstructive pulmonary disease (COPD) as a result of both the disease and aging. Some methods have been proposed to assess body composition (and therefore identify muscle mass loss) in this population. Despite the high accuracy of some methods, they require sophisticated and costly equipment.

Aim: The purpose of this study was to infer the occurrence of muscle mass loss measured by a sophisticated method (dual energy X-ray absorptiometry [DEXA]) using a more simple and affordable equipment (dynamometer).

Methods: Fifty-seven stable subjects with COPD were evaluated for anthropometric characteristics, lung function, functional exercise capacity, body composition, and peripheral muscle strength. A binary logistic regression model verified whether knee-extension strength (measured by dynamometry) could infer muscle mass loss (from DEXA).

Results: Patients with decreased knee-extension strength were 5.93 times more likely to have muscle mass loss, regardless of sex, disease stage, and functional exercise capacity $(P=0.045)$.

Conclusion: Knee-extension dynamometry was able to infer muscle mass loss in patients with COPD.

Keywords: COPD, sarcopenia, peripheral muscle strength

\section{Introduction}

Chronic obstructive pulmonary disease (COPD) is characterized by a variety of pathophysiological conditions and clinical manifestations that contribute to the heterogeneity of patient profiles. ${ }^{1}$ This disease is a major cause of chronic morbidity and the fourth leading cause of mortality worldwide. It is estimated that, in 2020, it will be the third highest cause of death worldwide. ${ }^{2,3}$

Among the systemic manifestations observed in COPD are the progressive decrease of skeletal muscle mass and the presence of several bioenergetic abnormalities, mainly expressed by low body weight. ${ }^{1}$ The disease's systemic effects can greatly increase the clinical symptoms, such as limitation of exercise capacity and peripheral muscle weakness and can have a negative impact on quality of life. ${ }^{4,5}$ Weight loss and low body mass index (BMI) have been suggested to be associated with worse health status and higher mortality rates in these patients. ${ }^{6-8}$

The aging process initiates sarcopenia, a syndrome characterized by progressive decrease of strength and muscle mass. ${ }^{9,10}$ Muscle mass loss is prevalent in patients with COPD as a result of both the disease and aging. ${ }^{11-13}$

Pulmonary rehabilitation programs are aimed at maintenance or improvement of physical and nutritional condition of individuals with COPD. ${ }^{14}$ In this sense, the 
assessment of patients' peripheral muscle strength and body composition is important to provide them an appropriate treatment and follow-up their progress during pulmonary rehabilitation programs. ${ }^{14}$

A few methods have been proposed to assess body composition in this patient population. ${ }^{15}$ Despite some of them being highly accurate, they require sophisticated and costly equipment, such as Dual Energy X-Ray Absorptiometry (DEXA), restricting its applicability in the clinical practice. Thus, from a clinical perspective, a method should be practical, portable, and inexpensive. ${ }^{16-18}$

Given the negative impact on quality of life that peripheral muscle strength and muscle mass may have due to the presence of systemic alterations, there is a clear need for studies proving the benefits of simple and accessible assessment tools that can be widely used in clinical practice in patients with COPD.

The purpose of this study was to verify whether it was possible to infer the occurrence of muscle mass loss measured by a sophisticated method (DEXA) using a more simple and affordable equipment (dynamometer).

\section{Methods}

\section{Participants}

The study participants were patients with COPD referred to the Pulmonary Rehabilitation Center for Studies, of the Faculty of Sciences and Technology, UNESP, Presidente Prudente, São Paulo, Brazil. The criteria for participant selection were diagnosis of COPD according to the (Global initiative for chronic Obstructive Lung Disease) GOLD criteria $^{19}$ and clinical stability with no exacerbations or changes in medication for at least 30 days. The exclusion criterion was the presence of disabling pathological conditions that could potentially influence physical activity performance, such as cerebrovascular diseases, rheumatism, and arthritis. A total of 57 patients were included in the study.

The study was approved by the institutional review board, the Ethics Committee of São Paulo Sate University/ Presidente Prudente, (Protocol number 95/2009), and all individuals signed an informed consent before participating in the study.

\section{Outcome measures}

Patients included in the study were evaluated for their anthropometric characteristics, lung function, functional exercise capacity, body composition, and peripheral muscle strength.
Body weight was measured on a digital balance accurate to $0.1 \mathrm{~kg}$ (Welmy R/I 200; Welmy, São Paulo, Brazil). Height was determined using a stadiometer accurate to $1 \mathrm{~cm}$ (Sanny; American Medical Do Brasil Ltda, São Bernardo do Campo, Brazil). BMI was calculated as the ratio of body weight $(\mathrm{kg})$ and height squared $\left(\mathrm{cm}^{2}\right)\left(\mathrm{BMI}=\right.$ body weight $/$ height $\left.{ }^{2}\right)$.

Lung function was assessed by spirometry using a portable spirometer Spirobank, version 3.6; (MIR, Rome, Italy) and performed according to the guidelines of the American Thoracic Society and European Respiratory Society. ${ }^{20}$ The reference values were specific for the Brazilian population. $^{21}$

The 6-minute walk test (6MWT) was used to assess functional exercise capacity according to the guidelines of the American Thoracic Society. ${ }^{22}$ Results obtained were referred and compared to normal values. ${ }^{23}$

Peripheral muscle strength tests of knee flexion and extension, shoulder flexion and abduction, and elbow flexion were performed unilaterally (dominant limb) with a digital dynamometer (Force Gauge ${ }^{\circledR}$ brand, FG -100 kg, Sao Paulo, Brazil), and the results were expressed in Newton (N). The volunteers performed a maximal voluntary isometric contraction for 6 seconds followed by limb relaxation. The measurement was repeated thrice with intervals of 1 minute, and the highest value was recorded.

The lean mass was assessed by DEXA (Hologic model QDR machine dials 2000/Plus; Hologic, Waltham, MA, USA) Software version 5.56. ${ }^{24}$ The ratio of appendicular lean mass (upper limbs lean mass + lower limbs lean mass [kg]/ height $[\mathrm{m}]^{2}$ ) was calculated and used to classify subjects into high lean mass (HLM) or low lean mass (LLM). Men with values lower than $7.91 \mathrm{~kg} / \mathrm{m}^{2}$ and women with values lower than $5.52 \mathrm{~kg} / \mathrm{m}^{2}$ were considered sarcopenic and included in the LLM. The adoption of these cut-off points was based on two standard deviations below the mean of a youth group ( $n=30,20$ men and ten women) aged between 20 and 30 years old, according to the recommendations of Baumgartner et al. ${ }^{25}$ Therefore, values below 206.4 and $144.5 \mathrm{~N}$ for knee extension, 112 and $72.7 \mathrm{~N}$ for knee flexion, 62.9 and $39 \mathrm{~N}$ for shoulder flexion, 58.8 and $33.6 \mathrm{~N}$ for shoulder abduction, and 116 and $59.2 \mathrm{~N}$ for elbow flexion, for men and women, respectively were considered as LLM.

\section{Data analysis}

Data were presented as mean and standard deviation. Data distribution was tested by the Shapiro-Wilk test. The mean values for each variable were compared between the groups (HLM and LLM) by the unpaired Student's $t$-test. 
The chi-square test was used to compare the proportion of patients above and below the cut-offs of muscle strength (see "Methods" section) in LLM. A binary logistic regression model was created to express the magnitude of the associations by odds ratio values (OR). In this model, the outcomes of muscle strength, sex, disease severity (GOLD), and functional exercise capacity were set as independent variables. Then, we verified the association between the variables in the model and each of the five tested muscle groups (knee extension/flexion, shoulder flexion/abduction, and elbow flexion). Statistical analysis was performed using SPSS software (SPSS Inc., Chicago, IL, USA) version 17.0, and significance level was set at $5 \%$.

\section{Results}

Fifty-seven patients participated in the study, of them 20 were women (forced expiratory volume in the first second $\left[\mathrm{FEV}_{1}\right], 44 \pm 14.1$ percentage of predicted values [\%pred]) and 37 were men $\left(\mathrm{FEV}_{1}, 52.6 \pm 19.9 \%\right.$ pred $)$. There was no significant difference in spirometric characteristics between men and women $(P=0.091)$.

Patients' anthropometric characteristics, their values of upper and lower limbs muscle strength, and the comparison between HLM and LLM are shown in Table 1. Twenty-five patients (19 men and six women) had sarcopenia and were included in the LLM group. Men with LLM had lower weight, BMI, appendicular lean mass, and lower knee extension strength than nonsarcopenic individuals $(P<0.01$ for all). In the LLM women group, there was lower appendicular lean mass than in HLM group $(P=0.011)$.

The results from the association between muscle strength tests for each movement and LLM can be seen in Table 2. Only knee extension presented a significant association. Patients with decreased knee extension strength were 5.93 times more likely to have low lean mass, regardless of sex, disease stage, and functional exercise capacity $(P=0.045)$.

\section{Discussion}

The present investigation showed that the use of a dynamometer to assess peripheral muscle strength, specifically the knee-extension strength, was able to infer muscle mass loss in patients with COPD.

Few studies have focused on the relationship between muscle strength and muscle mass in subjects with COPD. Villaca et $\mathrm{al}^{26}$ correlated dynamometry and the leg lean volume measured by DEXA. Hillman et $\mathrm{al}^{27}$ investigated the relationships of body composition and peripheral muscle strength (measured by dynamometry) with 6-minute walk distance. This is the first study that aimed at verifying the extent to which it was possible to infer muscle lean mass based on muscle strength.

We observed that knee-extension strength was highly associated with muscle mass depletion. Studies have demonstrated a relationship between peripheral muscle dysfunction and local tissue depletion in patients with COPD. ${ }^{15,28-30}$ Franssen et $\mathrm{al}^{30}$ described different adaptations in muscles of lower and upper limbs after a training program. Furthermore, it is also described that individuals may have lower lean mass index with preserved muscle strength. ${ }^{26}$ This may explain why we only found significant association with lower limb force and not with any of the tested upper limb groups.

Hillman et $\mathrm{al}^{27}$ observed a correlation between the quadriceps strength measured with a dynamometer and the lower limb muscle mass measured by DEXA. In their study, it was shown that the measure of muscle mass by DEXA was not able to add clinical information on muscle function from that observed by the simple measure from a

Table I General characteristics of the sample and comparison between groups with high lean mass and low lean mass

\begin{tabular}{|c|c|c|c|c|c|c|c|c|}
\hline \multirow[t]{2}{*}{ Variables } & \multicolumn{2}{|l|}{ Men $(n=37)$} & \multirow[t]{2}{*}{$t$} & \multirow[t]{2}{*}{$P$} & \multicolumn{2}{|c|}{ Women $(n=20)$} & \multirow[t]{2}{*}{$t$} & \multirow[t]{2}{*}{$P$} \\
\hline & HLM ( ( 8) & LLM (19) & & & HLM (14) & LLM (6) & & \\
\hline Age (years) & $68.6 \pm 9.0$ & $69.2 \pm 7.3$ & -0.212 & 0.833 & $62.7 \pm 9.5$ & $66.7 \pm 10.4$ & -0.656 & 0.521 \\
\hline Height $(\mathrm{cm})$ & $169.0 \pm 3.5$ & $168.0 \pm 6.0$ & 0.455 & 0.652 & $154.5 \pm 8.6$ & $|54.3 \pm 5|$. & 0.032 & 0.975 \\
\hline Weight (kg) & $80.9 \pm 7.9$ & $68.6 \pm 10.8$ & 2.977 & 0.005 & $61.8 \pm 14.3$ & $58.5 \pm 3.5$ & 0.386 & 0.704 \\
\hline BMI $\left(\mathrm{kg} / \mathrm{m}^{2}\right)$ & $28.3 \pm 2.6$ & $24.3 \pm 3.6$ & 2.958 & 0.006 & $25.8 \pm 5.0$ & $24.5 \pm 0.5$ & 0.417 & 0.682 \\
\hline Appendicular lean body mass $\left(\mathrm{kg} / \mathrm{m}^{2}\right)$ & $8.4 \pm 0.6$ & $7.0 \pm 0.4$ & 7.552 & 0.000 & $6.3 \pm 0.6$ & $5.2 \pm 0.1$ & 2.832 & 0.011 \\
\hline Knee extension $(\mathrm{N})$ & $269.6 \pm 104.3$ & $199.9 \pm 55.9$ & 2.554 & 0.015 & $146.3 \pm 36.3$ & $|24.8 \pm 3| .6$ & 0.954 & 0.353 \\
\hline Knee flexion $(\mathrm{N})$ & $|18.8 \pm| 4.2$ & $110.1 \pm 24.1$ & 0.959 & 0.344 & $75.6 \pm 23.1$ & $70.3 \pm 5.8$ & 0.388 & 0.703 \\
\hline Shoulder flexion $(\mathrm{N})$ & $63.7 \pm 17.5$ & $61.8 \pm 21.2$ & 0.235 & 0.816 & $41.6 \pm 12.7$ & $39.7 \pm 18.2$ & 0.221 & 0.828 \\
\hline Shoulder abduction (N) & $60.8 \pm 20.0$ & $56.1 \pm 18.0$ & 0.639 & 0.527 & $36.7 \pm 11.7$ & $35.7 \pm 10.2$ & 0.138 & 0.892 \\
\hline
\end{tabular}

Note: The data are expressed in mean and $( \pm)$ standard deviation.

Abbreviations: BMI, body mass index; HLM, high lean mass; LLM, low lean mass; N, newton. 
Table 2 Association between low lean mass and muscle strength and functional exercise capacity in COPD patients

\begin{tabular}{|c|c|c|c|}
\hline \multirow[t]{2}{*}{ Variables } & \multicolumn{3}{|c|}{ Low lean mass } \\
\hline & n (\%) & OR (Cl 95\%) & $P$ \\
\hline \multicolumn{4}{|c|}{ Knee extension } \\
\hline Higher & $12(21.4)$ & 1.00 & \multirow[t]{2}{*}{0.045} \\
\hline Lower & $20(35.7)$ & $5.93(1.04-33.74)$ & \\
\hline \multicolumn{4}{|c|}{ Knee flexion } \\
\hline Higher & $14(25)$ & 1.00 & \multirow[t]{2}{*}{0.298} \\
\hline Lower & $18(32.1)$ & $2.20(0.49-9.68)$ & \\
\hline \multicolumn{4}{|c|}{ Shoulder flexion } \\
\hline Higher & $16(28.6)$ & 1.00 & \multirow[t]{2}{*}{0.898} \\
\hline Lower & $16(28.6)$ & $0.91(0.20-4.02)$ & \\
\hline \multicolumn{4}{|c|}{ Shoulder abduction } \\
\hline Higher & $15(26.8)$ & 1.00 & \multirow[t]{2}{*}{0.848} \\
\hline Lower & $17(30.3)$ & $0.86(0.19-3.85)$ & \\
\hline \multicolumn{4}{|c|}{ Functional exercise capacity } \\
\hline Higher & $14(25)$ & 1.00 & \multirow[t]{2}{*}{0.112} \\
\hline Lower & $18(32.1)$ & $0.82(0.054-1.357)$ & \\
\hline
\end{tabular}

Abbreviations: OR, odds ratio; $\mathrm{Cl}$, confidence interval.

dynamometer. ${ }^{27}$ These results are not in line with our findings. We used a fixed dynamometer to evaluate the muscle force while Hillman et $\mathrm{al}^{27}$ used a hand-held dynamometer. This difference in the applied methodology may explain the contrasting results.

In our study, muscle mass loss could be inferred by knee-extension strength. A simple, affordable, and widely used measurement in clinical practice provides an idea of muscle characteristics apart from strength. The clinical applicability of our findings is related to an accessible alternative to infer the muscle composition of patients with COPD. This type of evaluation allows the elaboration of a more appropriate therapy and hence, optimizes the treatment of these patients.

A potential limitation of the study is that the sample size was not enough for the results to be extrapolated to the entire population of COPD. Although the establishment of cut-off values of dynamometry to categorize patients into HLM or LLM was not the primary aim of the present study, further research with larger sample would be indicated for this purpose.

In conclusion, despite the small sample, a simple and inexpensive technique proved to be able to infer muscle mass loss in patients with COPD.

\section{Acknowledgments}

This work was supported by the following Brazilian Scientific Agencies: Fundação de Amparo à Pesquisa do Estado de São Paulo (FAPESP), Programa Institucional da Pró-Reitoria de Extensão - PROEX/UNESP and FUNDUNESP.

\section{Disclosure}

The authors have no financial or nonfinancial conflicts of interest with any company referred to in this article.

\section{References}

1. Agusti AGN, Noguera A, Sauleda J, et al. Systemic effects of chronic obstructive pulmonary disease. Eur Respir J. 2003;21:347-360.

2. Global Initiative for Chronic Obstructive Lung Disease (GOLD). Global Strategy for the Diagnosis, Management and Prevention of COPD. 2011. Available from: http://www.goldcopd.org/. Accessed May 18, 2015.

3. Mathers CD, Loncar D. Projections of global mortality and burden of disease from 2002 to 2030. PLoS Med. 2006;3(11):e442.

4. Baarends EM, Schols PB, Mostert R, et al. Peak exercise response in relation to tissue depletion in patients with chronic obstructive pulmonary disease. Eur Respir J. 1997;10:2807-2813.

5. Shoup R, Dalsky G, Warner S, et al. Body composition and healthrelated quality of life in patients with obstructive airways disease. Eur Respir J. 1997;10:1576-1580.

6. Celli BR, Cote CG, Marin JM, et al. The body-mass index, airflow obstruction, dyspnoea, and exercise capacity index in chronic obstructive pulmonary disease. $N$ Engl J Med. 2004;350:1005-1012.

7. Shepherd A. The nutritional management of COPD: an overview. $\mathrm{Br}$ J Nurs. 2010;19(9):559-562.

8. Landbo C, Prescott EVA, Lange P, et al. Prognostic value of nutritional status in chronic obstructive pulmonary disease (COPD) patients. Am J Respir Crit Care Med. 1999;160(6):1856-1861.

9. Cruz-Jentoft AJ, Baeyens JP, Bauer JM, et al. Sarcopenia: European consensus on definition and diagnosis. Report of the European Working Group on Sarcopenia in Older People. Age Aging. 2010;39: 412-423.

10. Fernandez-Montero M, Rexach-Serra JA. Role of exercise on sarcopenia in the elderly. Eur J Phys Rehabil Med. 2013;49:131-143.

11. Roubenoff R. Sarcopenia: effects on body composition and function. J Gerontol A Biol Sci Med Sci. 2003;58:1012-1017.

12. Morley JE, Thomas DR, Wilson MM. Cachexia: pathophysiology and clinical relevance. Am J Clin Nutr. 2006;83:735-743.

13. Gelberg J, McIvor RA. Overcoming gaps in the management of chronic obstructive pulmonary disease in older patients: new insights. Drugs Aging. 2010;27:367-375.

14. Troosters T, Demeyer H, Hornikx M, Camillo CA, Janssens W. Pulmonary rehabilitation. Clin Chest Med. 2014;35(1):241-249.

15. Bernard S, LeBlanc P, Whittom F, et al. Peripheral muscle weakness in patients with chronic obstructive pulmonary disease. Am J Respir Crit Care Med. 1998;158:629-634.

16. Steiner MC, Barton RL, Singh SJ, Morgan MD. Bedside methods versus dual energy X-ray absorptiometry for body composition measurement in COPD. Eur Respir J. 2002;19:626-631.

17. Engelen MP, Schols AM, Heidendal GA, Wouters EF. Dual-energy X-ray absorptiometry in the clinical evaluation of body composition and bone mineral density in patients with chronic obstructive pulmonary disease. Am J Clin Nutr. 1998;68:1298-1303.

18. Kilduff LP, Fuld JP, Neder JA, et al. Clinical relevance of inter-method differences in fat-free mass estimation in chronic obstructive pulmonary disease. Respiration. 2003;70:585-593.

19. GOLD Scientific Committee. Global strategy for the diagnosis, management and prevention of chronic obstructive pulmonary disease. Available from: http://www.goldchronic obstructive pulmonary disease. org/. Accessed September 24, 2009.

20. Miller MR, Crapo R, Hankinson J, et al. Standardisation of spirometry. II: ATS/ERS Task Force: standardisation of lung function testing. Eur Resp J. 2005;26:319-338.

21. Duarte AA, Pereira CA, Rodrigues SC. Validation of new Brazilian predicted values for forced spirometry in Caucasians and comparison with predicted values obtained using other reference equations. J Bras Pneumol. 2007;33(5):527-535. 
22. ATS Committee on Proficiency Standards for Clinical Pulmonary Function Laboratories. ATS statement: guidelines for the six-minute walk test. Am J Respir Crit Care Med. 2002;166(1):111-117.

23. Enright PL, Sherrill DL. Reference equations for the six minute walk in healthy adults. Am J Respir Crit Care Med. 1998;158:1384-1387.

24. Li C, Ford ES, Zhao G, et al. Estimates of body composition with dual-energy X-ray absorptiometry in adults. Am J Clin Nutr. 2009;90: 1457-1465.

25. Baumgartner RN, Koehler KM, Gallagher D, et al. Epidemiology of sarcopenia among the elderly in New Mexico. Am J Epidemiol. 1998;147: 755-763.

26. Villaca DS, Lerario MC, dal Corso S, et al. Clinical value of anthropometric estimates of leg lean volume in nutritionally depleted and non-depleted patients with chronic obstructive pulmonary disease. $\mathrm{Br}$ J Nutr. 2008;100:380-386.
27. Hillman CM, Heineche EL, Hii JW, Cecins NM, Jekins SC, Eastwood PR. Relationship between body composition, peripheral muscle strength and functional exercise capacity in patients with severe chronic obstructive pulmonary disease. Intern Med J. 2012;42:578-581

28. Serres I, Hayot M, Prefaut C, Mercier J. Skeletal muscle abnormalities in patients with COPD: contribution to exercise intolerance. $\mathrm{Med} \mathrm{Sci}$ Sports Exerc. 1998;30:1019-1027.

29. Yoshikawa M, Yoneda T, Takenaka H, et al. Distribution of muscle mass and maximal exercise performance in patients with COPD. Chest 2001;119:93-98.

30. Franssen FM, Broekhuizen R, Janssen PP, Wouters EF, Schols AM Limb muscle dysfunction in COPD: effects of muscle wasting and exercise training. Med Sci Sports Exerc. 2005;37:2-9.

International Journal of COPD

\section{Publish your work in this journal}

The International Journal of COPD is an international, peer-reviewed journal of therapeutics and pharmacology focusing on concise rapid reporting of clinical studies and reviews in COPD. Special focus is given to the pathophysiological processes underlying the disease, intervention programs, patient focused education, and self management protocols.

\section{Dovepress}

This journal is indexed on PubMed Central, MedLine and CAS. The manuscript management system is completely online and includes a very quick and fair peer-review system, which is all easy to use. Visit http://www.dovepress.com/testimonials.php to read real quotes from published authors.

Submit your manuscript here: http://www.dovepress.com/international-journal-of-chronic-obstructive-pulmonary-disease-journal 